\title{
Still Going Strong in Tennessee
}

\section{from our Special Correspondent, Knoxville, Tennessee, November}

THE Oak Ridge National Laboratory, 30 miles or so away from this the nearest airport, remains one of the few places where it is possible to recapture that magic air of the forties when nuclear energy was still new, and when it seemed prudent to everybody concerned with it that nuclear research stations should be tucked comfortably away in isolated places. In the event, even after nearly a quarter of a century, the research station seems to have affected the surrounding country only in comparatively unimportant ways. Indeed, AlCoA remains the dominant industry in this town, with the University of Tennessec a close second. The Oak Ridge National Laboratory occupies a few of the most southerly undulations of the Appalachians. Nearby are the uranium-235 production plants.

The Oak Ridge National Laboratory has retained not just its isolation but much of the old daring of the postwar years. In other words, it differs markedly from many other laboratories. How has this come about? One obvious, if incomplete, answer is that the laboratory has somehow managed to retain its interest in and responsibility for a good deal of the straightforward reactor development which was the bread and butter of nuclear research establishments until comparatively recently. Of the $\$ 100$ million spent at the laboratory each year, the laboratory collects $\$ 40$ million from the AEC for reactor development, undertakes some $\$ 5$ million of reactor work on contract for other parts of the AEC, and also spends about $\$ 5$ million on thermonuclear research of various kinds. This means that the core of the laboratory's work is a programme of reactor development which is not outrageously different in scale from what has been done at Oak Ridge in the past twenty years, and which is still the largest item on the budget. People are perpetually reminded that the laboratory has a continuing purpose.

The director of the laboratory, Dr Alvin Weinberg, is quite explicit about the need for further developments in nuclear power. He says that "in my book, nuclear power hasn't got anywhere until there is an economical breeder reactor". Pride of place at Oak Ridge these days goes to a reactor experiment using molten salt loaded with enriched uranium as both fuel and coolant, and this could yet turn out to be the principle for making Dr Weinberg's dream come true. But this, he makes plain, is only a first target. Beyond that is the objective of using really cheap energy-less than 2 mills a $\mathrm{kWh}$-to distil water, produce steel from iron ore by direct reduction with hydrogen and, in general, to use cheap encrgy as a raw material, not a kind of lubricant for industrial processes. But really cheap energy will entail that somebody should exploit the economies which large scale makes possible, which implies aggregates of nuclear reactors turning out $20,000 \mathrm{MW}$ or more. This picture is openly acknowledged to be Wellsian, as is the view that "we are just not prepared to give up", but it accounts quite simply for the way in which the laboratory's programme hangs together and, at the same time, it gives those who work there a coherent target at which to aim. Even if Dr Weinberg turns out to be wrong about the future, he is probably right in his way of giving the laboratory a sense of purpose.

The molten salt reactor experiment is a relic of the attempt to provide a power plant for the now abandoned B70 nuclear aircraft. "The "salt" is a eutectic mixture of lithium, beryllium and zirconium fluorides (with the lithium enriched in lithium-7 to reduce neutron absorption). One virtue of the reactor experiment now running is that it is possible to carry heat away from the reactor simply by pumping the salt, laden with enriched uranium fluoride, through the channels built into the stack of graphite plates used as a moderator. For this thermal neutron system to function as a breeder, it would be necessary to operate on the uranium-233/thorium cycle, which is why the system is now being tried out with a charge of uranium233. In real life, a reactor core constructed along the lines of the four-foot barrel now in use would have to be surrounded by a separate system containing fertile molten salt (loaded with thorium). A working reactor would probably have a core some sixteen feet across and a power output of some hundreds of MW. One great advantage would be that chemical processing, like the removal of fission products, could be carried out continuously. A snag is that the conversion ratio of such a reactor would probably not exceed something like $1 \cdot 05$.

Experience so far with the reactor seems to have made everybody concerned with it extremely cheerful. Corrosion seems to have been less serious than at first feared-nickel alloys have helped to give the plumbing immunity, while the graphite has surprised everybody by its stoutness. It has turned out to be possible to keep the salt free from contaminants with which it would react, chiefly by a liberal use of helium for purging the system. Those concerned with the project seem anxious to get on with the design of a more realistic embodiment of this design in hardware, and are impatient at the prospect that money may be even harder to come by in the next fiscal year. There have been so many previous disappointments in similar fields that optimism is prudently discounted, yet there are also occasions when optimism has been justified.

The thermonuclear research programme is also moving forward steadily, although those concerned have distant goals in view. The centrepiece of the present programme is a machine for creating a magnetic well of the kind now familiar in several thermonuclear research laboratories, and which owes much to the initiative of the Russian physicist Ioffe. The principle is that the well is filled with plasma which is then heated by microwaves, when neutral atoms of deuterium or tritium are injected by means of an external molecular beam gun. One of the novelties of the new machine being built is the use of superconducting coils for supporting the magnetic well. Experience in the past few years has shown that this arrangement 


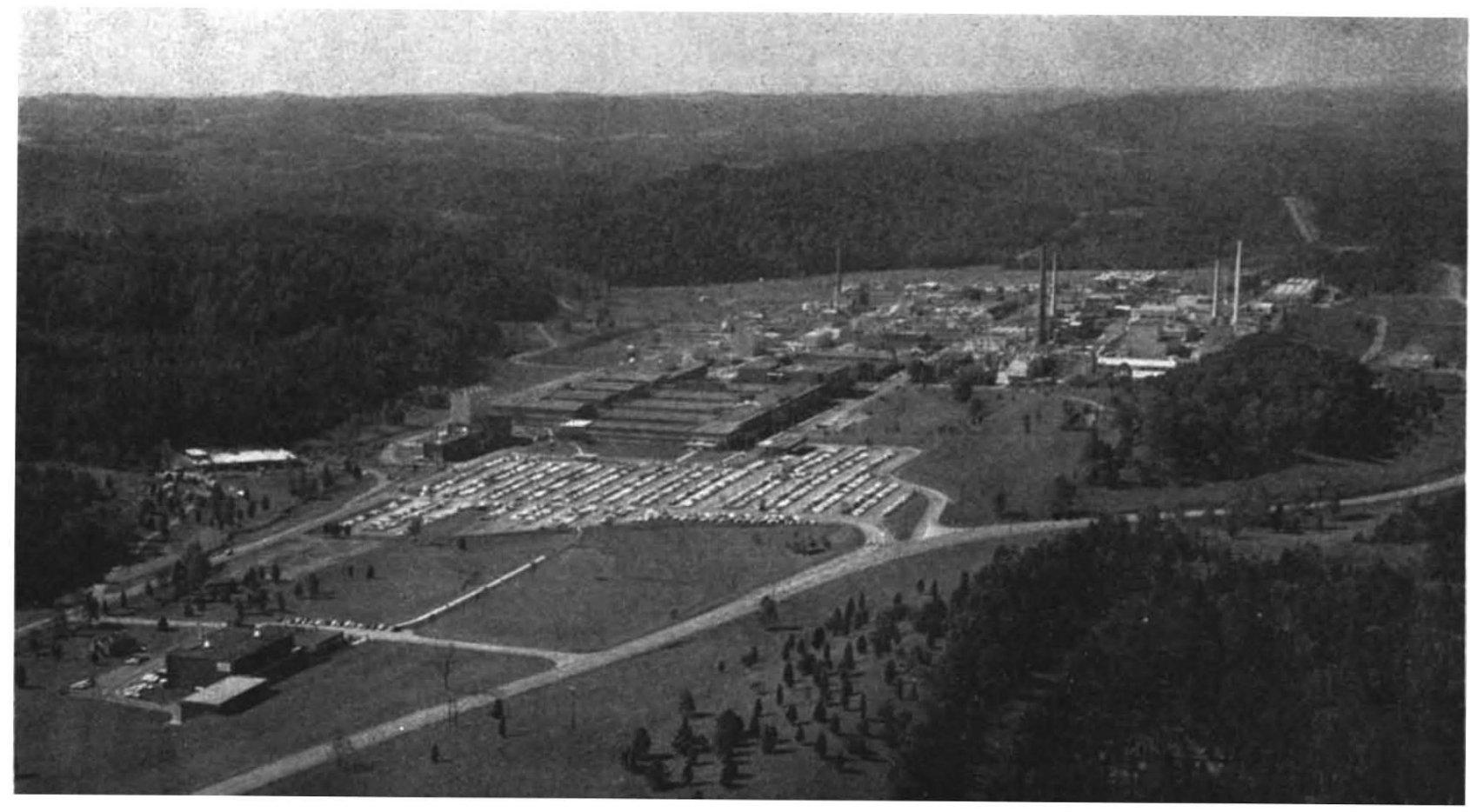

makes possible a comparatively efficient means of ionizing the neutral atoms fired at the target plasma and thus trapping them as well. Even so, it seems to be acknowledged as unlikely that, with the arrangement now being built, a density of deuterium or tritium nuclei greater than $10^{12}$ particles a cubic centimetre will be attained. This will be at least a couple of orders of magnitude below the density at which thermonuclear reactions produce more energy than the hot plasma consumes.

Like many other nuclear energy laboratories, the Oak Ridge National Laboratory is in the thick of desalination research. This is a natural accompaniment of the laboratory's view that ways of using nuclear energy are a natural part of its brief. The desalination programme, however, is less concerned with hardware than with the ways in which machinery may be used. The underlying philosophy is that improvements of agricultural practice in conjunction with irrigation offer the greatest likelihood of a dramatic improvement in the productivity of farmland. The laboratory has embarked on a programme of study in the Middle East and in the Ganges plain. Plans are being made for the establishment of a number of experimental farms each with perhaps 500 acres, a small distillation plant (not necessarily run by nuclear power) and a plentiful supply of agronomists.

Dr Weinberg is proud of the way in which his laboratory can quickly redeploy its interests in ways like this. He says that this is one of the great benefits of a multidisciplinary laboratory sustained by a hard core of enduring activity and with enough people to be flexible. In other words, he is trying to establish the view that redeployment is not a sudden reaction to adversity but, rather, a natural state of affairs for a good laboratory. Even though some of the projects which the laboratory has undertaken in the past few years-in the life sciences in particular-have not been outstandingly successful, this principle seems to have worked out well.

\section{Is a PhD Worth Having?}

A DETALLED sociological definition of the American $\mathrm{PhD}$ has been compiled by the Office of Scientific Personnel of the National Research Council in Washington, acting for the National Institutes of Health (Careers of PhDs-Academic versus Non-Academic, National Academy of Sciences, \$6). The report succeeds an earlier document, published in 1965, and is based on a survey among 10,000 people awarded $\mathrm{PhD}$ degrees between 1935 and 1960 . One of the chief objectives has been to understand the forces which distribute $\mathrm{PhDs}$ between academic and other jobs, but the statistics which have been collected also provide a description of the salary pattern in the scientific professions. Those in Britain who have been concerned about the large proportions of those with $\mathrm{PhD}$ degrees seeking to work in academic life-the Swann Committee, for example-may be surprised to be reminded of the academic proclivities of American PhDs.

The $\mathrm{PhD}$ graduates in the survey were chosen from the names of some 250,000 graduates on the lists of the Office of Scientific Personnel of the National Research Council. For the purposes of the survey, six groups of PhDs graduating in 1935, 40, 45, 50, 55 and 60 were sent questionnaires, and the replies were suitably weighted to account for failures to respond. For the 